\title{
Un/Seeing Campus Carry: Experiencing Gun Culture in Texas
}

\section{Benita Heiskanen}

\section{(2) OpenEdition \\ 1 Journals}

Electronic version

URL: https://journals.openedition.org/ejas/15817

DOI: 10.4000/ejas.15817

ISSN: 1991-9336

Publisher

European Association for American Studies

\section{Electronic reference}

Benita Heiskanen, "Un/Seeing Campus Carry: Experiencing Gun Culture in Texas", European journal of American studies [Online], 15-2 | 2020, Online since 07 December 2020, connection on 08 July 2021. URL: http://journals.openedition.org/ejas/15817 ; DOI: https://doi.org/10.4000/ejas.15817

This text was automatically generated on 8 July 2021 .

Creative Commons License 


\title{
Un/Seeing Campus Carry: Experiencing Gun Culture in Texas ${ }^{1}$
}

\author{
Benita Heiskanen
}

Politics revolves around what is seen and what can be said about it, around who has the ability to see and the talent to speak, around the properties of spaces and the possibilities of time.

Jacques Rancière, The Politics of Aesthetics

\section{Introduction}

1 On August 1, 2016, SB 11 or "Campus Carry" legislation that had been passed in 2015 went into effect in Texas. The law allows License to Carry (LTC) holders to bring their guns onto public university campuses. The University of Texas at Austin, a campus with a large student population, was forced to conform to the contentious law even though there were strong objections to it by members of the university community. ${ }^{2}$ The controversy surrounding the implementation process of Campus Carry made Austin the epicenter of national and international debates regarding individuals' and communities' sense of security and insecurity in educational contexts. Since the implementation of SB 11, there has been much sociocultural speculation in the United States and beyond about how the law affects Texas university campuses. This article is a direct response to that speculation. Based on fieldwork and interviews conducted in Austin, Texas in the spring semesters of 2018 and 2019, the discussion considers the ways in which members of The University of Texas at Austin community delineate their visual-spatial surroundings and sensory perceptions on campus before and after the implementation of the Campus Carry law. By considering a range of visual interventions by lawmakers and university administrators, as well as counter-visuals created by grassroots activists, faculty, and students, the article demonstrates the interrelatedness among policy-making, quotidian experiences, and visual culture viewpoints.

2 The imposition of the legislation in 2016 created an uproar among the university community, who condemned both its perceived ramifications on the learning 
environment and the symbolic consequences of the timing, with the implementation scheduled on the anniversary of the University Tower shooting fifty years earlier. ${ }^{3}$ On August 1, 1966, The University of Texas at Austin was a site for the first mass shooting at a US university. The sniper Charles Whitman, a 25-year-old UT Austin student and a war veteran, engaged in a 96-minute-long shooting rampage from the University Tower toward the main mall beneath it, leaving 14 people dead and 31 injured. In years to come, accounts of the murders, complete with portrayals of the shooter and his victims, were documented in such books and films as Gary Lavergne's A Sniper in the Tower (1997), Elizabeth Crook's Monday, Monday (2014), Keith Maitland's (dir.) The Tower (2013), and Jerry Jameson's (dir.) the Deadly Tower (1975), alongside many other popular culture representations. ${ }^{4}$ The Tower, which is the site of the University Main Building, stands in the middle of the campus and remains a material reminder of the tragedy. Yet for decades, The University of Texas's official policy was not to commemorate the tragedy in conspicuous ways. Classes resumed only a day after the shooting and evidence of the scene of the crime was erased. ${ }^{5}$ The university engaged in actively suppressing the memory of the shooting. ${ }^{6}$ In multiple ways, the institutional suppression resulted in what Yên Lê Espiritu characterizes as "organized forgetting." In this article, I take the notion of organized forgetting as a starting point for discussing the legacy of the Tower shooting and its ramifications on gun politics and culture on campus in the contemporary context. I argue that by engaging in a form of organized forgetting, the university attempted to suppress the issue of gun violence from memory, while anti-gun activists' visual interventions served as dissenting acts of memory-making to call attention to their experiences within the armed campus space.

In 1999, after three decades of silence, the university made a decision to dedicate the garden behind the Tower to the memory of the tragedy. However, as there was no signage pointing to its function as a memorial, it was not clear to outsiders what that dedicated space stood for. Eight years later in 2007, another decision was made to erect a plaque to commemorate those killed, wounded, or touched by the shooting. ${ }^{8}$ It took another nine years before the university erected a memorial in 2016, complete with the full names of the victims, in their honor. The text at the bottom of the memorial reads: "The University of Texas at Austin remembers with profound sorrow the tragedy of August 1, 1966. This space is dedicated as the Tower Garden, a memorial to those who died, to those who were wounded, and to the countless other victims who were immeasurably affected by the tragedy." For the first time in fifty years, both a visual and a verbal acknowledgement were made of the tragedy that had taken place on campus. ${ }^{9}$

4 This article establishes a bridge between the fifty years of organized forgetting and memory-making from the Tower shooting to the Campus Carry legislation. Moving beyond the much-discussed depictions of the sniper, the victims, and the rescuers of the Tower shooting, my main line of inquiry is to consider the ways in which members of the university community delineate their visual-spatial surroundings and sensory perceptions on campus before and after the implementation of the Campus Carry law. ${ }^{10}$ Drawing on fieldwork and interviews conducted with faculty, students, and university administrators, my discussion examines visual statements by lawmakers and university administrators promoting forgetting, as well as activist interventions by faculty and students reinstating processes of memory-making. ${ }^{11} \mathrm{I}$ am particularly interested in the where and how of memory-making and forgetting: how such processes are created and maintained, as well as who gets to participate in the creation and transformation of 
remembering. I explore these questions by looking at the ways that remembering and forgetting are linked with visual-spatial interventions which facilitate such processes. I first look at a range of visual statements by lawmakers and university administrators and then consider counter-visuals created by activists on campus. The visuals and counter-visuals demonstrate a tension between seeing and unseeing the armed campus space, revealing a range of metaphors through which guns may be discussed without exhibiting the actual, physical object of a gun.

Drawing on Jacques Rancière's work on the political dimension of aesthetics, I approach Campus Carry as an example of a particular aesthetic-political regime created by the state legislators and negotiated by the university community. My discussion on the implementation of gun legislation and the experiences of an armed campus is inspired by Rancière's notion that the "relations between saying, seeing and doing themselves belong to the structure of domination and subjection." ${ }^{12}$ The article demonstrates that the university's implementation of Campus Carry is based on the logic that firearms should not be seen, namely, that unseeing weapons is considered a safety issue. The imposition of SB 11 by the state of Texas resulted in aesthetic-political acts at the University that exemplify Rancière's characterization of "configurations of experience that create new modes of sense perception and induce novel forms of political subjectivity." ${ }^{13}$ For the purposes of my discussion, the aesthetic-political framework provides a lens to interrogate the ways in which campus communities experience, negotiate, and challenge processes of organized forgetting and memory-making. Here it is important to note that for Rancière the political is relational in nature, signifying political interventions, rather than partisan politics or governmental actions. Another cornerstone of his thinking is that aesthetics is at the very core of politics. For Rancière, aesthetics relates to broad sensory experiences, perceptions, and identifications of art, rather than traditional understanding of beauty..$^{14}$ By mapping quotidian experiences through a visual-spatial lens, this article offers a discussion of the theoretical and practical ramifications of SB 11 for the multiple parties involved, complete with broader questions of who gets to decide and participate in representational processes in public and private space.

\section{The Visual-Spatial Order as Forgetting}

6 The Campus Carry legislation resulted in active reformulations of campus space into zones where concealed guns may or may not be carried or where permissions shift, depending on the present purpose and users. The territory of these zones is communicated through an extensive body of signage, informational publications, and oral notices. The basic premise of SB 11 is that a License to Carry (LTC) holder may carry a firearm into a campus building unless it is part of an "exclusion zone" that has been identified by UT Austin policy or state or federal law. ${ }^{15} \mathrm{~A}$ legally concealed handgun on campus must be located "on or about" one's person (i.e., the handgun must be close enough so that one can grasp it without materially changing position). For example, if the handgun is carried in a backpack, the backpack must always remain close to the person's immediate reach. Presidents of Texas public universities were accorded the right to make "reasonable rules" regarding concealed carry on campus, including where handguns may not be carried, as long as they did not generally prohibit or have the effect of generally prohibiting the carrying of a handgun by a LTC 
holder. ${ }^{16}$ At UT Austin, a task force delineated the areas where guns may and may not be carried as follows: 1) handguns may always be present in most university buildings, lecture halls, and cafeterias, with a few exceptions (for example, sometimes a portion of a building is excluded); 2) handguns may never be carried in high hazard labs, daycare centers, any program for minors, sporting facilities, patient care areas (including mental health care), or animal research facilities; 3) handguns may not be carried by LTC holders in campus residence halls, yet they are allowed in common areas, such as lounges, dining areas, and study areas. A resident's licensed family members may carry in the resident's room while visiting, and a licensed full-time staff member who lives in University housing may carry and store their handgun in their room. Moreover, UT Austin University Apartments (so-called married couples' housing) allows the carrying and storage of handguns. ${ }^{17}$

During the implementation process, a major issue arose whether the university would provide gun safes for LTC holders; in the end, citing safety reasons, the task force prohibited the storage of handguns on campus, but permitted the storage of guns in vehicles. As a result, parking places became the only legally available gun repositories on campus. A university administrator involved with the implementation process describes the rationale as follows:

We didn't want storage, because we felt that, number one, storage exposed an individual. If they are going there and putting a weapon in, it exposes you as somebody who is carrying a weapon .... What we were trying to prevent was the number of times weapons are handled. So, if you are taking it off of your belt or out of your boot and putting it in, that's another time it's handled. Looking for accidental discharges and trying to minimize that. Then, the third reason was, it'd become kind of a magnet. If I'm wanting to steal guns and I see somebody put a gun in there, if I want to steal a gun, I know where to go look for guns, so to speak. So that was kind of our rationale for not providing storage. ${ }^{18}$

The logic of concealed carry and its implementation is premised on the notion that guns should not be seen, in that concealing weapons is first and foremost a safety measure, both for the carrier and for the university community. One is not allowed to ask anybody whether they are carrying a firearm, and license holders are not allowed to show their weapons in public. In exclusion zones, such as sporting arenas when athletic events are going on, spectators are expected to carry see-through plastic bags, so that the organizers can check their belongings and ensure that guns are not being brought onto the premises.

The zoning that emerged on campus as a result of the legislation is informative in its assumption about the campus community's spatial maneuvering and sensory perceptions of guns-or lack thereof. The exclusion zones are communicated by the university through a body of signage in compliance with state law. The only official sign prohibiting a concealed carrier from entering a building or enterprise is the one based on Texas State Penal Code 30.06. To be legal, the sign must meet the size and English and Spanish language requirements established by the state. 


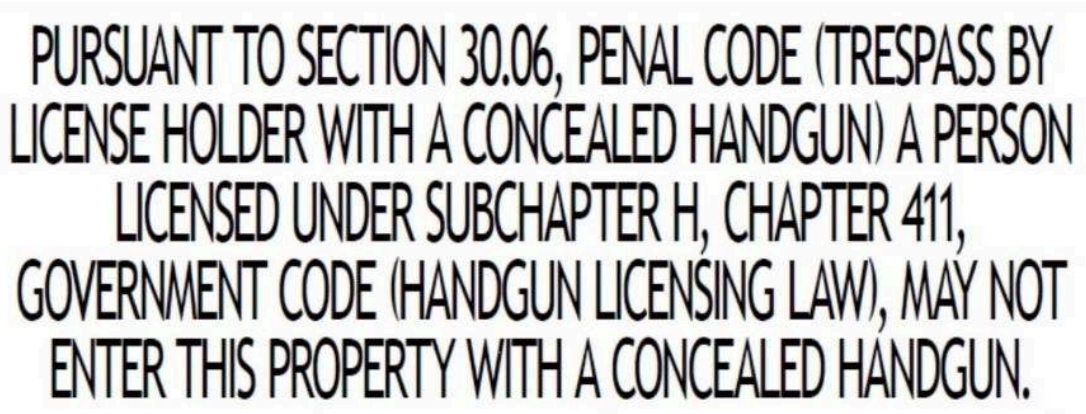

SEGGIN LA SECCOON 30.06 DEL CODGO PENLL (ALLANAWENTO POR PERSONA CON LCENCA DE ARMAS PORTANDO UN ARMA

OCULTA),SE PROHBBE LA ENTRADA EN ESTA PROPIEDADA TODA PERSONA PORTANDO UN ARMA OCULTA, NCLLIDAS AQUELLAS PERSONAS CON LCENCIA AUTORZADAS POR EL CAPTTLLO 411, SUBCAPTULO H, DEL CODIGO DE GOBIERNO (QUE REGULA LA LLCENCIA DE TENENCIA DEARMAS).

Image 1. Texas State Penal Code 30.06 sign on campus. Courtesy of The University of Texas at Austin.

This sign may only be posted by officials of the University, and they also determine where the signs are located. No other sign, regardless of how informative it may be, is considered legally binding. It is the responsibility of LTC holders to know where a handgun can and cannot be carried. Only two buildings, the Student Services Building and an animal research complex, are complete exclusion areas. Most of the signs can be found outside of "high hazard" laboratories (defined by the types and quantities of particular chemicals), animal research facilities, and patient care areas. Sometimes the sign is only posted for part of the day, such as at the Texas Memorial Stadium: "If you go to the stadium today, the stadium is open. You can go and jog the track, you can carry in the stadium because there's not an intercollegiate event, so therefore the 30.06 sign is covered. But yet on a football game, we uncover that sign, so you know not to bring your weapon to the game."19

The sign prohibiting Open Carry, based on Penal Code 30.07, is not seen on campus proper, yet it can be found within its immediate vicinity on buildings that are adjacent to campus. Juxtaposing the signage on and off-campus reveals a conspicuous detail: the ones on campus do not show the image of a gun, whereas the ones adjacent to it do. The incongruity of this practice signals contradictory attitudes: while university officials maintain that the presence of guns will not have a detrimental effect on campus, the visual suppression of the image of the gun suggests an opposite value judgment, namely, that the presence of guns-albeit concealed-is not desirable. 


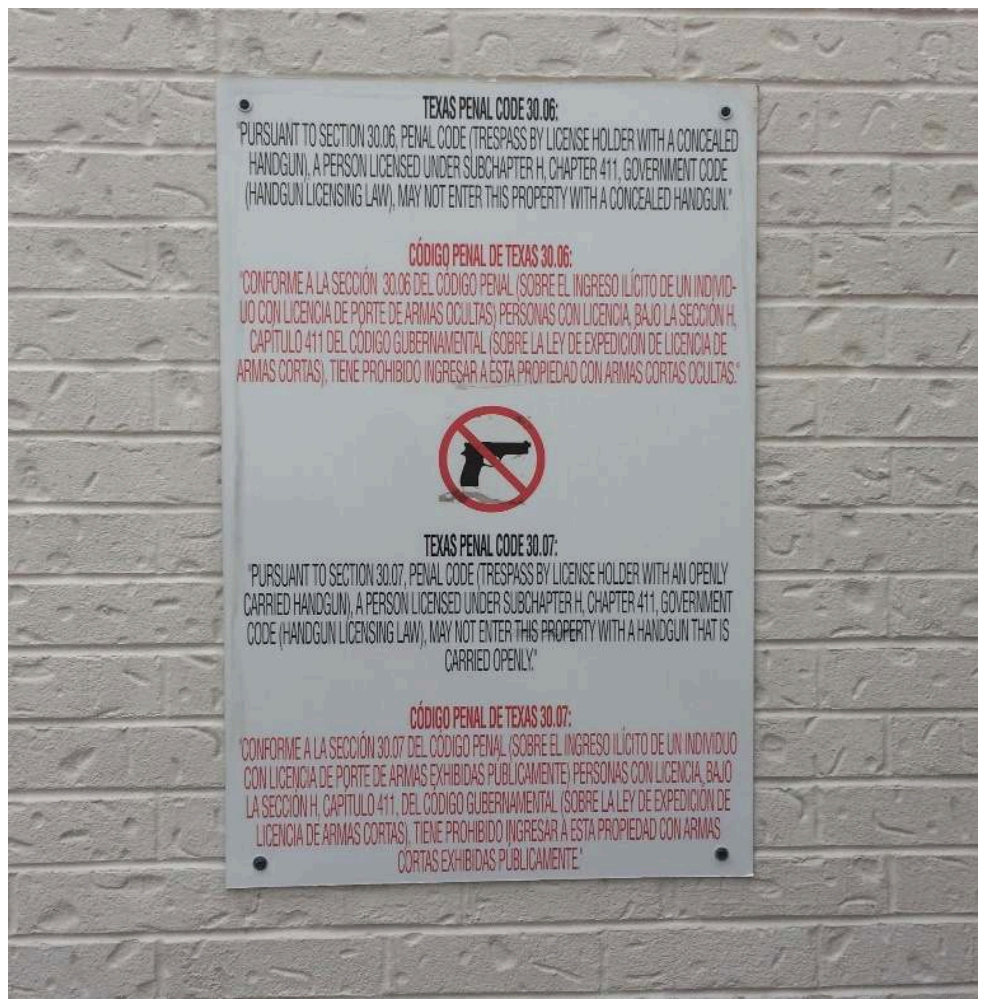

Image 2. Texas State Penal Code 30.06 and 30.07 sign off-campus. Photo: Benita Heiskanen. Courtesy of the John Morton Center for North American Studies.

Another sign mandated by state law is the " $51 \%$ sign," which dictates that handguns may not be carried into any business that gets $51 \%$ or more of its income from the sale or service of alcohol.
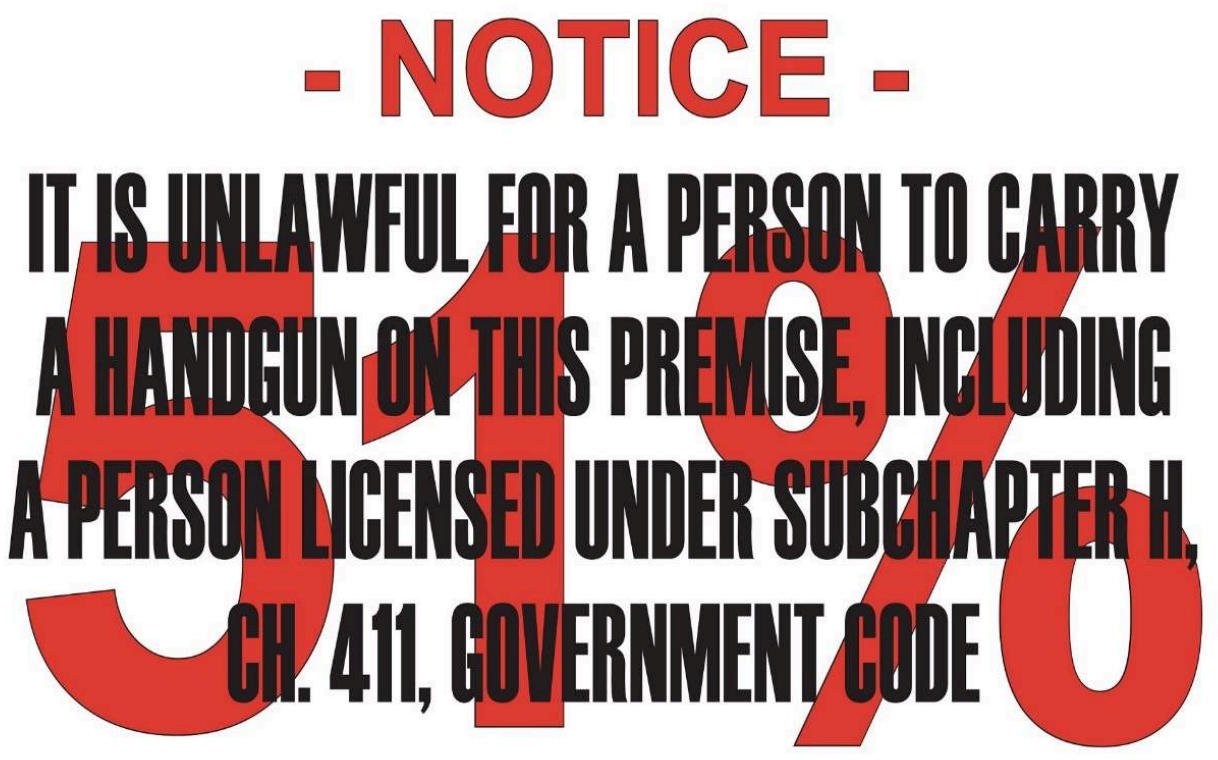

Image 3. 51\%. Courtesy of The University of Texas at Austin.

After the implementation of the law, bars on campus-such as Cactus Café and Gabriel's -displayed the 51\% sign on their premises. However, university administrators were challenged by a threat of a lawsuit arguing that the former is part of the Student Union and the latter is in a building that houses a hotel and, therefore, 51\% of the income of 
these buildings does not actually come from alcohol sales. As a result, the sign displayed in both of these establishments was changed to one specifying the need for a license to carry in order to enter:

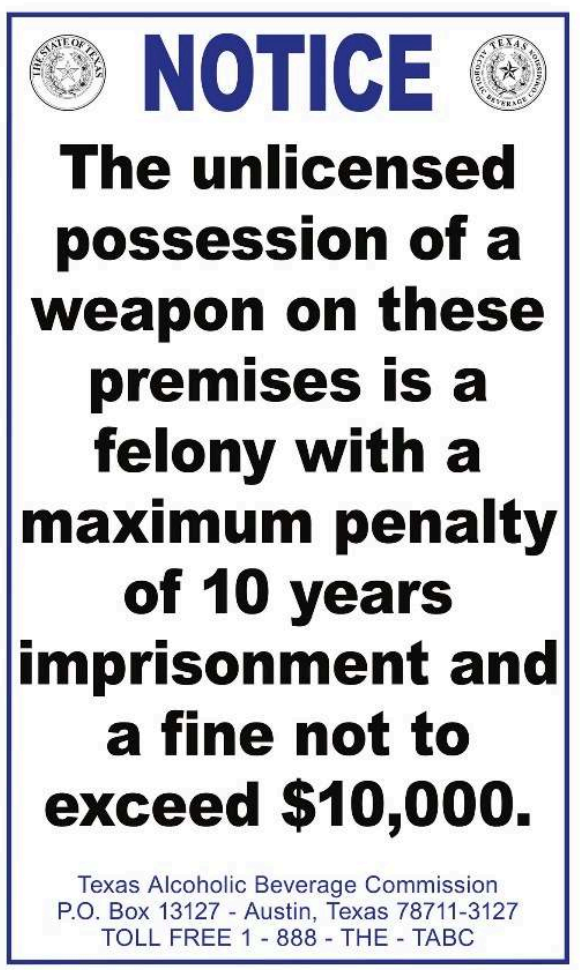

Image 4. Texas Alcoholic Beverage Commission Notice. Courtesy of The University of Texas at Austin.

The Campus Carry law is linked to broader ideological assumptions about constitutional rights in public, semi-public, and private space. The pro-gun contingency based their arguments on the Second Amendment right to practice selfdefense and the freedom to make their own choices about guns. The anti-gun contingency argued that the First Amendment granted them the right to exercise freedom of speech without any external threats. Much of the debating and negotiating around the implementation of the law took place behind the scenes, comprising a territorial power play between the pro- and anti-gun forces on campus. Moreover, as the above examples testify, the implementation of the law continues to be dynamic, as university administrators are met with challenges by interest groups taking issue with SB 11 and its everyday ramifications in practice.

In addition to Texas state laws, there are areas on campus that fall under the jurisdiction of federal laws prohibiting the carrying of handguns on their premises. Such buildings include the LBJ Presidential Library, the Nuclear Engineering Teaching Laboratory, and the University Post Office on campus. 


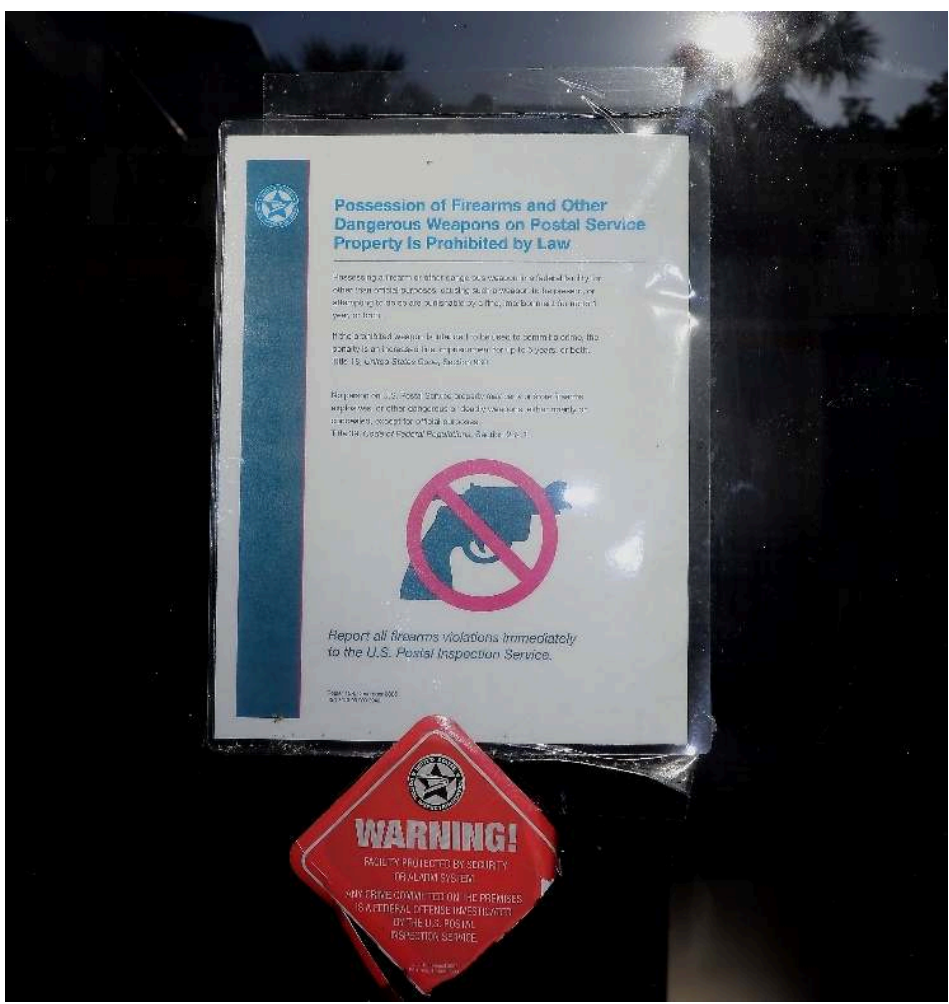

Image 5. Title 39, Code of Federal Regulations, Section 232.1 sign. Photo: Lotta Kähkönen. Courtesy of the John Morton Center for North American Studies.

At times, an area is only excluded for a small period of time while a particular activity takes place. For example, guns are prohibited during university hearings, active polling places, and during K-12 school programs. School-sponsored events include field trips to specific parts of campus, which require the specific area to be determined as an exclusion zone, complete with appropriate signage in place. In these instances, the signage is not dictated by Texas state law, but University policy, as in the following: 


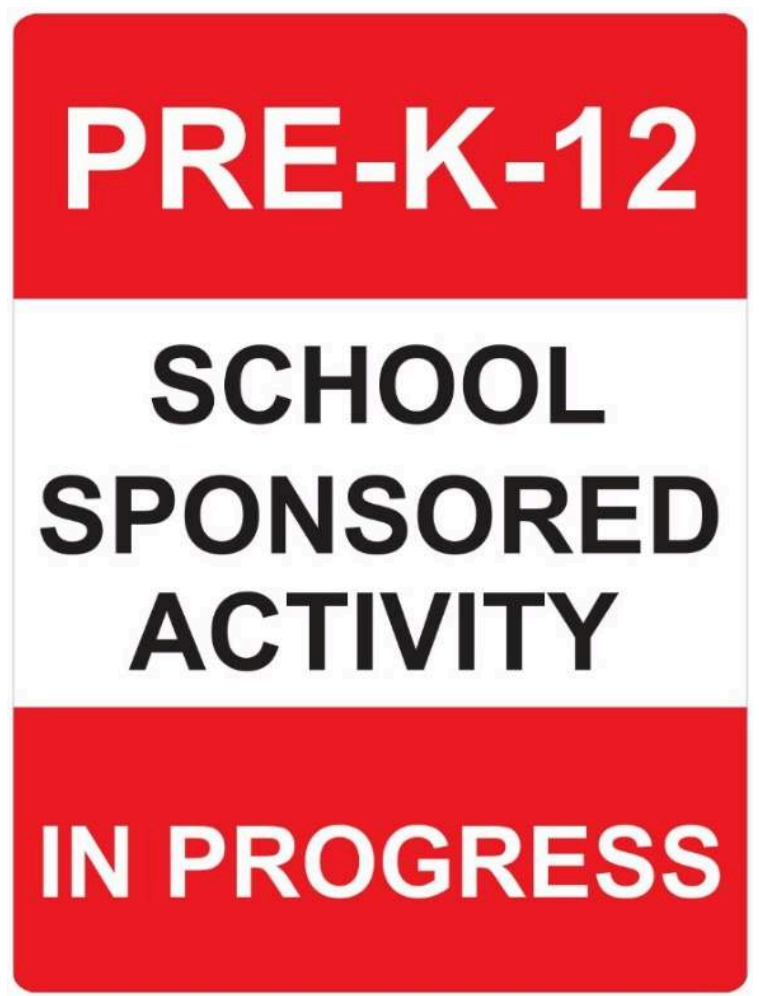

Image 6. School Sponsored Activity sign. Courtesy of The University of Texas at Austin.

The purpose of the sign is informational, rather than regulatory. The understood target group for the sign is the carriers; non-carriers have no way of deciphering that the sign has to do with firearms. That was the explicit intention of the leadership of the university as well as the administrators delineating the law's implementation in practice:

See, the idea is that as a concealed carrier, a licensed concealed carrier, I know when I see that sign that there's a school activity. I can't carry. So, I don't put up a sign out there that says, "There's a school activity. Nobody can carry a gun today." We thought there was no sense to alarm the normal community, but you had to alert the concealed carrier [about] what he could do and what he couldn't do. ${ }^{20}$

The same logic applies to active polling places, ${ }^{21}$ where it is the sole responsibility of the license holder to know where a handgun can and cannot be carried:

We have some buildings that are used as temporary polling places during general election time.... By state law, the only requirement for that is that there is a polling place sign-up and a "Vote Here" -or something that identifies it as a polling place. Those two meet the regulatory needs, so we have no other type of signage that is put up during those instances. It is the onus of licensed-to-carry holders to realize that they cannot take a concealed handgun to a polling place, so by just seeing a "polling here" sign, it meets the intent of the law. ${ }^{22}$ 


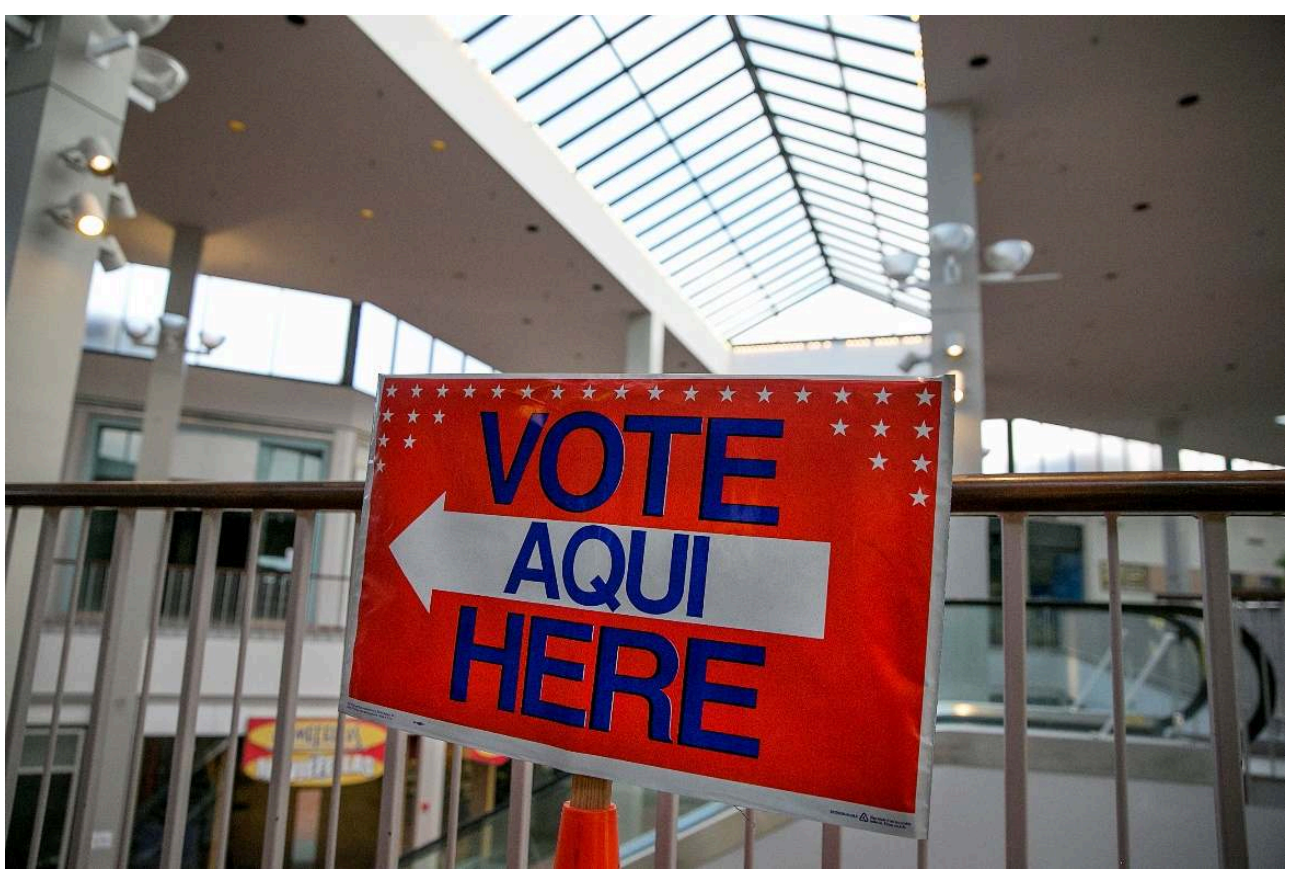

Image 7. Vote Aqui/Here sign. Courtesy of The University of Texas at Austin.

The absence of a visual image of guns in the university policy signs creates a certain cognitive dissonance with the reality that specifically allows the campus to be armed. Yet the university policy was intentional: "Because it is concealed, people don't know who is carrying or not carrying. They have no idea how many people are carrying or not carrying, and as long as no major issue comes up, as a result of it people just get used to it and carry on and pretty much forget about it." ${ }^{23}$ The suppression of images of guns, then, serves as a specific example of organized forgetting by which the university attempts to suppress the "memory" of guns-and potential threat of gun violencefrom visual perception.

Consequently, The University of Texas at Austin knowingly removed all images of guns from its gun-policy related signage. Compare, for example, the official UT Austin 30.06 sign to the one at the entrance of St. Edward's University-a private educational establishment in Austin-that prohibits guns on campus: 


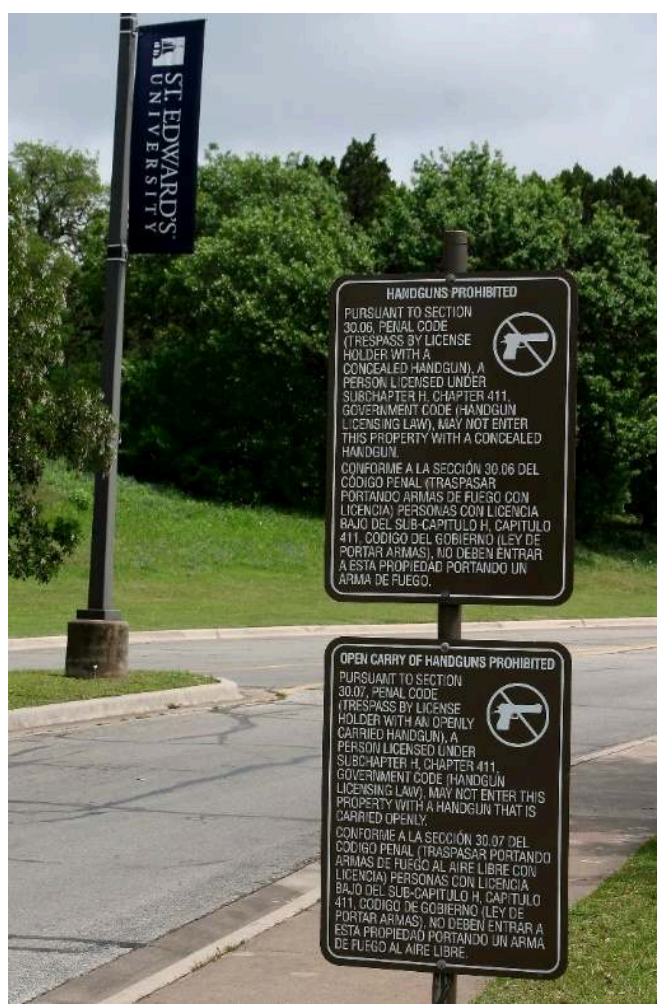

Image 8. Entrance to St. Edward's University, Austin, Texas. Photo: Albion M. Butters. Courtesy of the John Morton Center for North American Studies.

Allowing guns on campuses but at the same time barring visual depictions of them on signage led to some obvious discrepancies. First, as interviewees for this article were quick to point out, UT Austin is an armed campus! Secondly, if the belief is that guns will not have a detrimental effect on campus, a logical question that follows is: Why should images of them be visually suppressed from the topography of the campus? In its positioning, the university presupposes what Rancière deems as the "intolerable reality" of images, where the image of reality itself becomes suspect: "What it shows is deemed too real, too intolerably real to be offered in the form of an image." ${ }^{24}$ In other words, the presence of guns is acceptable, but seeing them (and, by extension, representations of them) is not. The University administrators maintained that as long as guns-including mere images of them-were suppressed from visual perception, actively unseen, the policy implementation was successful. At the same time, grassroots interventions by activists were cementing their opposition to the law by means of tangible and conspicuous visual statements in shared space to impose their own version of memory-making, in order to challenge attempts at organized forgetting.

\section{Visual Interventions as Acts of Memory-Making}

Faculty activism against Campus Carry has been vocal and visible ever since the UT community became knowledgeable of the imminent legislation in 2015. The tension between the First and Second Amendments to the Constitution assumed meaning within the context of higher education, with various epistemological consequences. The main question posed was, what impact would the presence of guns-albeit concealed ones-have on knowledge production processes? In two town hall-style 
meetings organized by the University prior to the implementation of the legislation, both the pro- and anti-Campus Carry contingencies had a chance to express their viewpoints..$^{25}$ The proponents emphasized the crux of the issue, as they saw it, as a fundamental right for individuals to practice self-defense, as determined by the Supreme Court case District of Columbia v. Heller in 2008. In their opinion, violence on campus would decrease when so-called "good guys with guns" could function as a deterrent. The argument went that law-abiding "good guys" were needed to counter "bad guys" who did not respect the law. Moreover, the pro-gun contingency argued, licensed women would be better able to defend themselves against assault. The antigun contingency delineated the discussion around freedom of speech: that the threatening presence of guns had a chilling effect in the classroom, which was meant to be a sanctuary for the free exchange of ideas and a safe space for learning. Their argument maintained that guns undermined the freedom to seek and debate the truth -especially in relation to sensitive and controversial issues-and the right to safety and life. Countering the pro-gun contingency's insistence on the right to bear arms, antigun proponents demanded what their rights were as teachers in academia.

The epistemological fight against SB 11 was led by the largest anti-gun activist group on campus, Gun Free UT, a grassroots organization comprising UT faculty, staff, students, alumni, family, and community. Their campaign was largely centered around "GUN FREE UT" signs and "ARMED WITH REASON" graphics printed on bright orange and posted on office windows and doors:

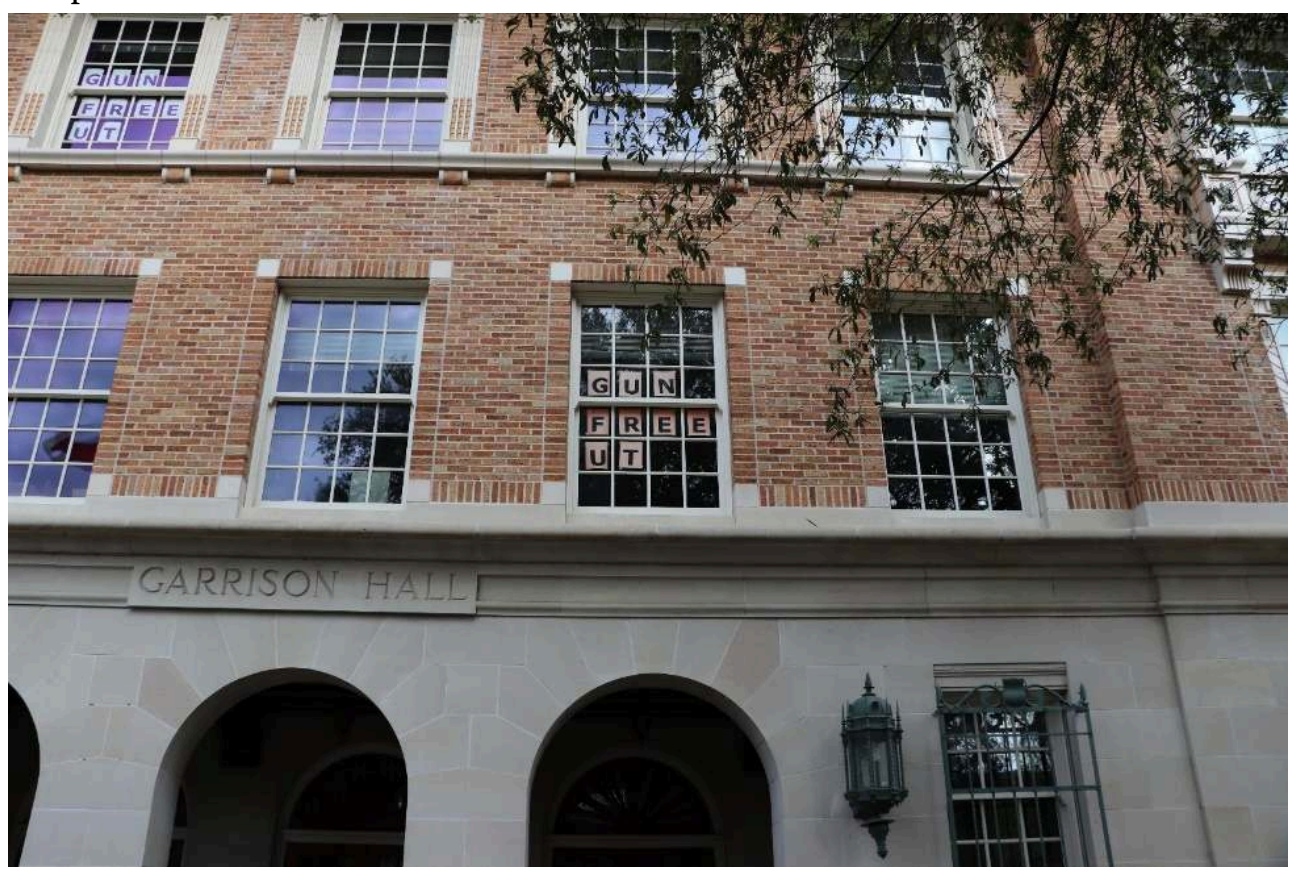

Image 8. GUN FREE UT sign. Photo: Benita Heiskanen. Courtesy of the John Morton Center for North American Studies. 


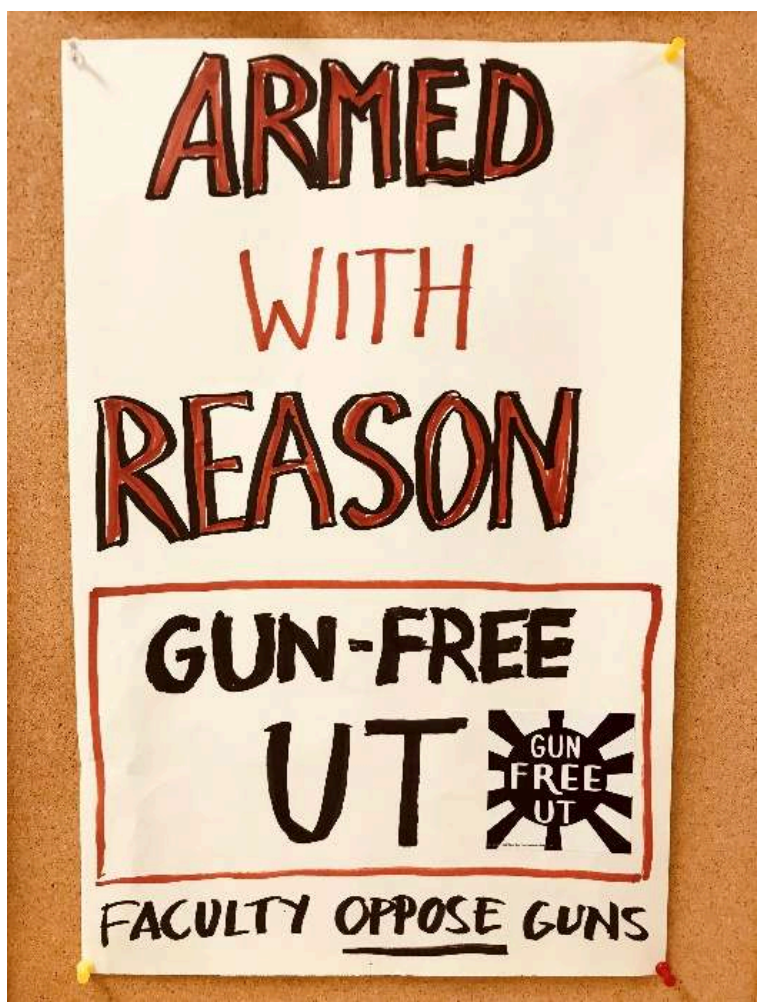

Image 9. ARMED WITH REASON sign. Photo: Benita Heiskanen. Courtesy of the John Morton Center for North American Studies.

To complicate the pro-gun contingency's representations of gun carriers, members of the Gun Free UT group used posters and online discussions to ask, "Who is the Bad Guy with a Gun?" Conversely, they challenged, "Who is the Good Guy with a Gun?" The presence of the GUN FREE UT signs prompted a similar response as the $51 \%$ signs discussed in the previous section. The university administrators allegedly received complaints from pro-gun groups, arguing that the signs were detrimental to the public image of the university and represented a one-sided take on the issue. However, a faculty member of the anti-gun faction saw the signs as "political dialogue," emphasizing, "This is our First Amendment right and we want to talk about things. That's our job." ${ }^{26}$ The purpose of the signs was to keep the resistance movement going and maintain awareness of the issue, even though the anti-gun activists themselves had scant hope that their activities would have any actual impact in terms of overturning the legislation.

Although UT grassroots activists were insisting on keeping alive the memory of gun policy debates on campus, The University of Texas resorted to what amounted to another measure of organized forgetting. On September 6, 2018, citing official signage policy, UT requested that faculty take down GUN FREE UT signs from "outward facing" windows. ${ }^{27}$ According to a comment by a university spokesperson,

All students, faculty and staff have the right of free speech and expression on the UT Austin campus.

Consistent with U.S Supreme Court rulings, the university has policies that use a content-neutral approach based on "time, place and manner" to regulate speech on campus, including the placement of signs. The University's rules do not allow signs on windows that face externally to campus. ${ }^{28}$ 

plethora of notices on office doors contributing to a visual landscape not conducive to a learning environment:

We did not want a situation where when you walk down the hall of any building where there are offices, someone would see a gun sign after a gun sign after a gun 
sign after a gun sign. ... What came to my mind immediately was, we are recruiting somebody to join our faculty and, walking around, what do they see about this campus? Guns. Every office they go to, they would see a sign, because almost every faculty member would put such a sign up if they could. That would so overemphasize the importance of this issue on this campus. It would make it seem like this was the predominant thing that this campus was about is guns. ${ }^{33}$ that did not violate the law but overtly criticized its implementation. Consider, for example, the following signs found across campus, if mainly in buildings housing humanities and social sciences, and generally not the hard sciences.

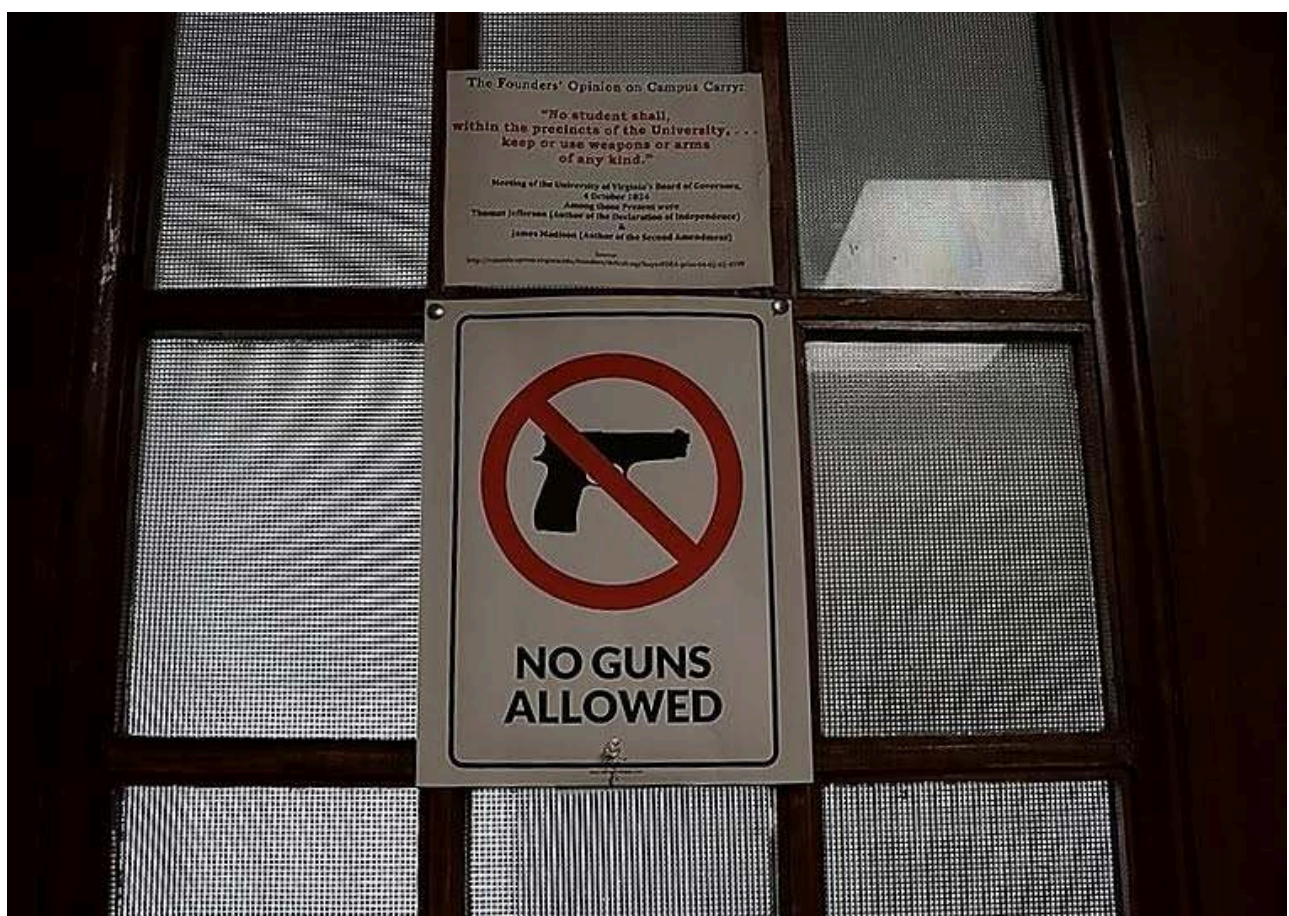

Image 10. UVa quote and unofficial "No Guns Allowed" sign, History Department.

Photo: Benita Heiskanen. Courtesy of the John Morton Center for North American Studies.

In the image above, the anti-gun message-"No student shall within the precincts of the university, keep or use weapons of any kind"-quotes a contrasting weapons policy that was established at a different time and place. Taken from a meeting of a University of Virginia Board of Governors, chaired by Thomas Jefferson and James Madison in 1824, this quotation provides the reader with historical context and precedent. Here, the issue is not whether carrying firearms is constitutional; the point is to call attention to the Founding Fathers' negative opinion of students' right to "Campus Carry" on university premises. In the transcript of the original document, the punishment was no less than expulsion without appeal: "Fighting with weapons which may inflict death, or a challenge to such fight, given or accepted, shall be punished by instant expulsion from the University, not remissible by the Faculty." ${ }^{44}$ Given that gun rights proponents frequently refer to the Founding Fathers to justify their position, this form of visual irony serves as a valid counter-argument for the opposing side.

The following sign at UT Austin's German Department takes issue with the policy dictating oral notifications in lieu of visual signage by not only defiantly posting a 
picture and text communicating no guns allowed but also presenting a written "contract" to document that oral notification has been issued.

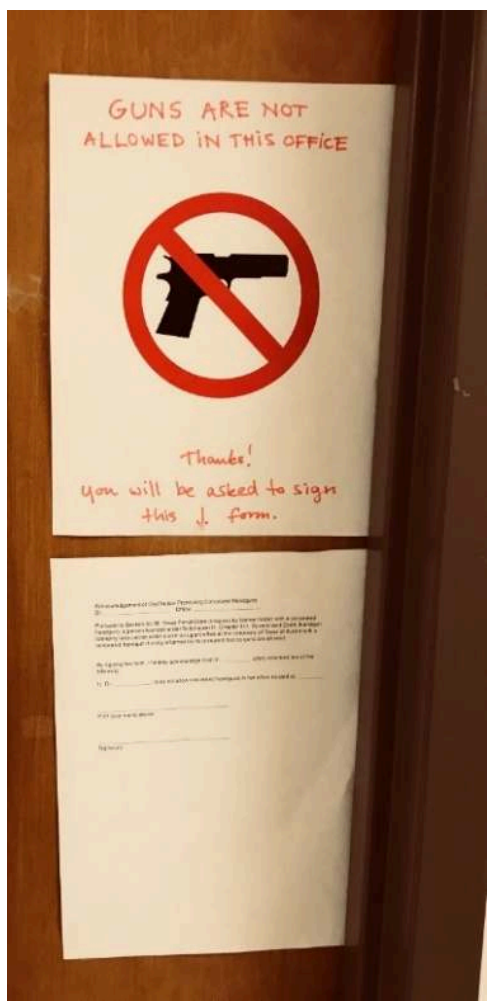

Image 11. Unofficial "No Guns Allowed" sign and contract, German Department. Photo: Benita Heiskanen. Courtesy of the John Morton Center for North American Studies.

In both of the instances above, by specifically deploying visual images of guns, faculty members resisted the measures taken toward organized forgetting by university administrators and instead augmented the memory that they worked within an armed campus space.

Not all resisting visual statements draw on traditional imagery. Akin to the official signs that did not display any visual image of guns, the activists' statements opposing the presence of guns in offices reference implicit, cultural tropes to get their message across. Animal motifs in general, and furry cat imagery in particular, were used as tools to channel displeasure about guns on campus, with intentional queering of university policy requiring individual oral notifications. The juxtaposition of a cute kitty with discussions of firearms underscored the cognitive dissonance of having guns on campus. 


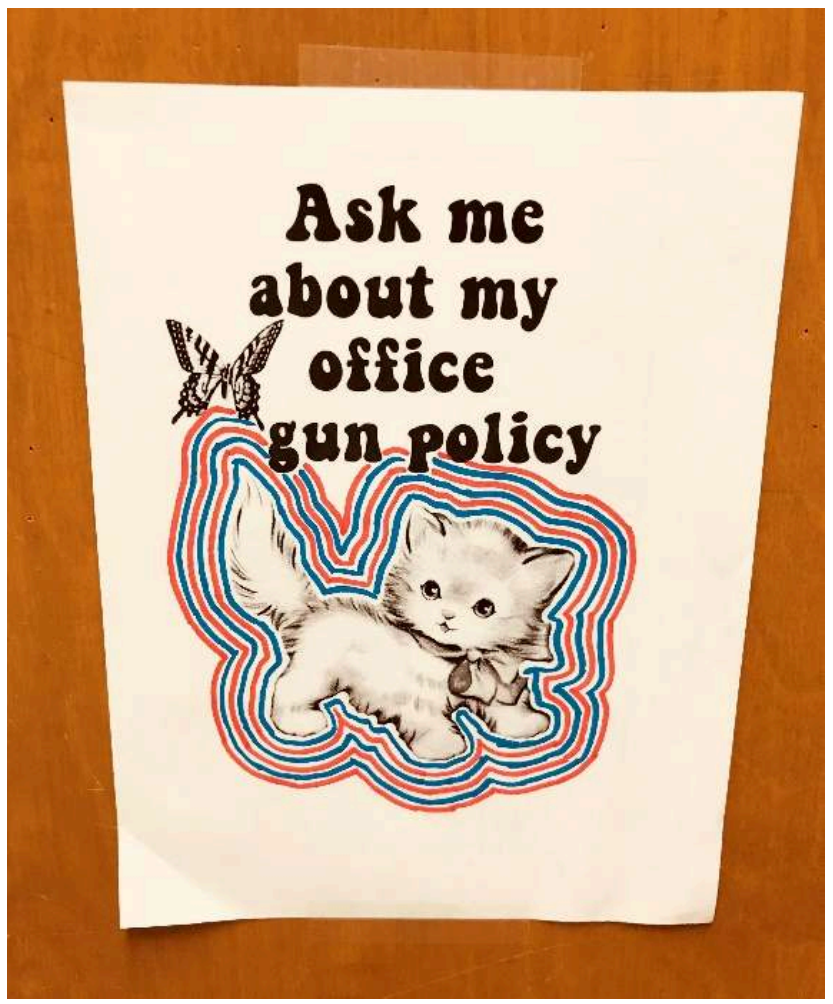

Image 12. Furry cat sign, Department of American Studies. Photo: Benita Heiskanen. Courtesy of the John Morton Center for North American Studies.

A range of other popular culture images was also common, as in the following graphic image on a pink background:

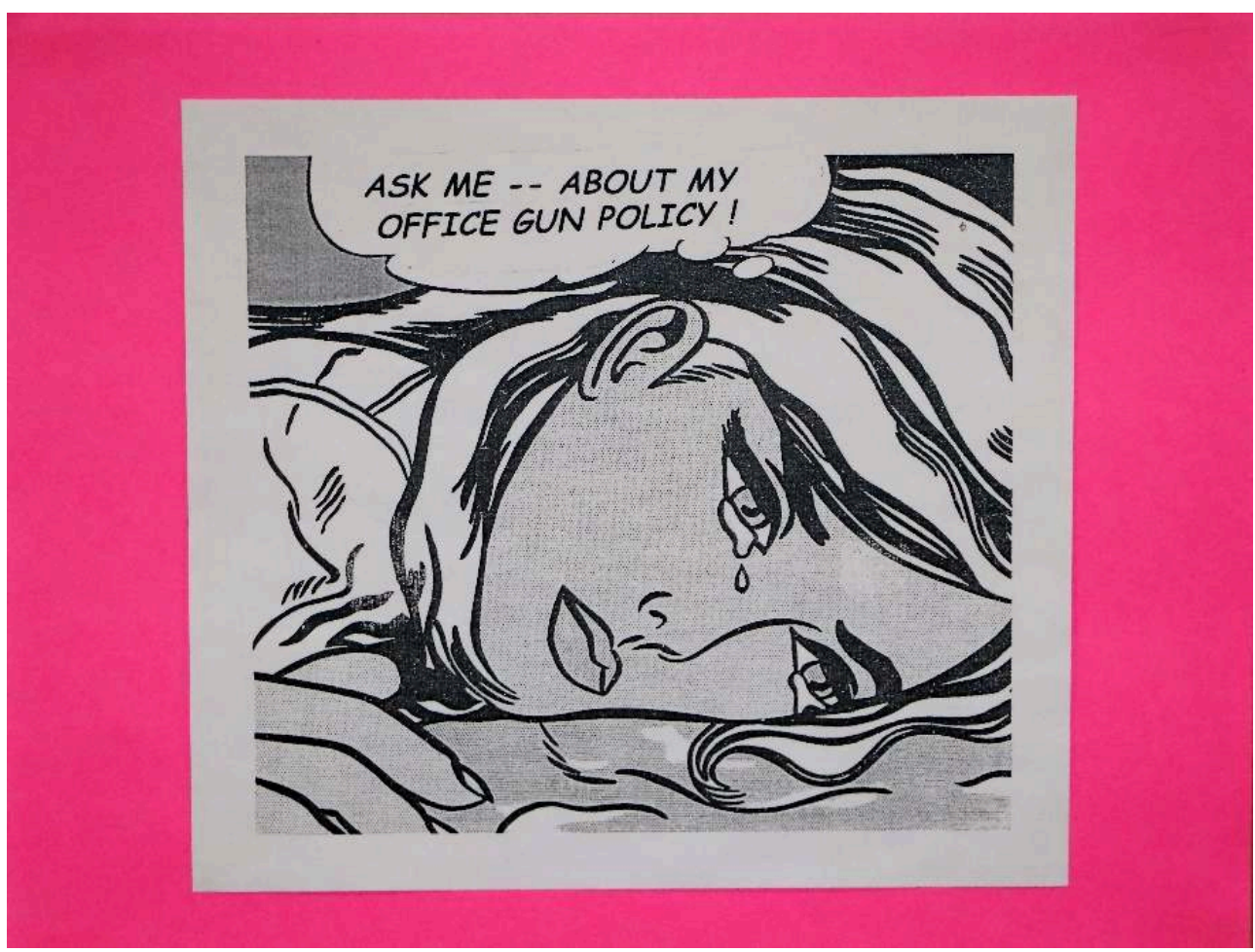

Image 13. Pop-art “Gun Policy” sign, Department of English. Photo: Lotta Kähkönen. Courtesy of the John Morton Center for North American Studies. 

question of how much one is looking/seeing or looking away/unseeing one's reality through the medium of these images. These questions, in turn, tie the act of looking/ seeing to broader actions: do we see or do we attempt to "un-see" what is around us and, in both cases, whose interests do we hold dear at heart? Asbjørn Grønstad and Henrik Gustafsson inquire about the motives of a person choosing not to look: "Does not looking absolve us from complicity, or is the ostensibly respectful act of averting one's eyes in fact to deny responsibility and foreclose knowledge?" ${ }^{37}$ In the instance of Campus Carry, visual imagery becomes key for both organized forgetting and memorymaking. As evidenced by the examples discussed here, the visuals and counter-visuals related to SB 11 serve the purposes of members of the University community in multiple ways. The heterogeneous official and unofficial signs prompted by the SB 11 legislation respectively reinforce and challenge the imposition of the legislation on the campus community, highlighting individuals' rights to maneuver within public, private, and shared space as determined by both state and federal law, as well as university policy.

\section{Conclusion}

This article's visual-spatial lens provides a way to penetrate policy discourses through a people-centered focus that interrogates the ways in which campus communities experience, negotiate, and challenge questions of security and insecurity imposed by gun laws and their implementation. The contestation of the aesthetic-political order occurs when some parties seek to express dissenting views on a contentious policy issue imposed by state legislators. My examination suggests that a people-centered visual-spatial approach offers a fruitful way to delineate the significance of gun laws within educational establishments in the United States. The many competing visual 
statements discussed in this article thus call attention to particular modes of knowledge production that are contested by competing agents of organized forgetting and memory-making within existing state, university, and inter-group hierarchies. The university's organized forgetting produces a lack of knowledge, or a suppression of knowledge, that seeks to hide the presence of firearms on campus. The officials who promote forgetting are enforcing state weapons laws while occluding their visibility, and those who are competing with them are doing it in an asymmetrical, unofficial manner. The strategies used by members of the community to delineate and critique the legislation exemplify the dynamic relationship between the various power players involved, ranging from state legislators, university administrators, stakeholders, and members of the university community, each with their ideological and political leanings.

On an everyday level, the contestation between organized forgetting and memorymaking at UT Austin has taken place primarily between university officials and antigun activists, with the administrators insisting on suppressing guns from the visual topography of campus space and activists reminding the public of the presence of guns through visual statements. The pro-gun contingency, which has little visual impact in campus space, effectively pushes its agenda through online forums, backdoor channels, and direct appeals to the university. Thus far, it seems to be on the winning side, as the university has in many instances bent to its will. The activists interviewed for this article who were against Campus Carry were well aware of the limited chance they had to effect a change. Although a group of professors filed a lawsuit against the state and the university based on the freedom of speech argument, there was little actual belief in the potential for success in court. ${ }^{38}$ As one activist put it:

My feeling about the lawsuit was that it was never going to be about winning or losing. It was really just going to be about creating a platform to be able to continue to express our dissent and to try to move the needle on public opinion about this law but really about the much broader question of the role of guns in school society in the United States. ${ }^{39}$

Given how little faith there was in the (now failed) lawsuit, it is small wonder that almost none of the activists considered overturning the Second Amendment to be feasible.

By way of a conclusion, I want to return to the memory-bridge between the Tower shooting in 1966 and the implementation of the Campus Carry legislation. In both instances, the issue has to do with seeing or unseeing guns and their potential impact on people operating in campus space. ${ }^{40}$ With or without visual imagery of guns, the University Tower continues to stand as a haunting landmark of events that took place over fifty years ago, while having left an indelible mark on both the campus and contemporaries who are still grappling with their memories. In the words of Claire Wilson, a survivor of the tragedy, "Every year, when August approaches, I start trying to forget... but as any rational person knows, when you try to forget something, you just end up thinking about it more." ${ }^{41}$

Wilson's statement captures the tension between fifty years of individual and collective memory-making and active forgetting that ensued from the tragedy. As with the Tower shooting, the University's first impetus with the Campus Carry legislation was to suppress visual reminders of guns on campus. Yet, examining everyday experiences of gun culture through the visual-spatial intersection of the where, what, and how reveals 
the intrinsic entanglement of organized forgetting, memory-making, and knowledgeproduction processes. By capturing the visual-spatial practices of the UT campus community in their quotidian surroundings, we may expose multiple linkages between policy-making, the aesthetic-political regime, and acts of dissent. The displaying of visual statements reveals the profoundly hierarchical nature of campus as place, with unequal claim to space by members of the university community. The assigning of space thus manifests as a top-down, bureaucratic process, one which is determined by rank and tenure. Through their ingenuity around production of visual images, however, members of the community may overstep their preconceived spatial boundaries and, in so doing, participate in public debate. Ultimately, the visual-spatial analytical approach to gun laws is important in that it does not reduce societal change to political abstraction alone, but calls attention to individuals' agency in dealing with everyday experiences of policy-making, from the grassroots up.

\section{NOTES}

1. This work was supported by the Academy of Finland grant 310568. I would like to express thanks to the anonymous reviewers and my colleagues in the Campus Carry research team for comments and suggestions on earlier drafts of the manuscript. Thanks also to all the interviewees and sources for this article, as well as the Department of American Studies at UT Austin, for hosting our fieldwork in Texas. A version of this paper was presented as a plenary address for the biannual NAAS conference in Bergen, Norway in April 2019.

2. At the time the law took effect, the student body at UT Austin numbered 50,950.

3. Shaundra K. Lewis and Daniel Alejandro De Luna, "Symposium on 'Texas Gun Law and the Future': The Fatal Flaws in Texas's Campus Carry Law," Thurgood Marshall Law Review, 41:2 (2016), 135-150.

4. Gary Lavergne, Sniper in the Tower: The Charles Whitman Murders (Denton, TX: University of North Texas Press, 1997); Elizabeth Crook, Monday, Monday (New York: Farrah, Strauss and Giraux, 2014); Keith Maitland, dir., Tower (ITVS, 2016); and Jerry Jameson, dir., The Deadly Tower (MGM, 1975).

5. "Behind the Tower: New Histories of the Tower Shooting," http:// behindthetower.org/, accessed July 7, 2019.

6. On the various ways in which the 1966 shootings have been remembered and forgotten, see Rosa A. Eberly, "Everywhere You Go, It's There': Forgetting and Remembering the University of Texas Tower Shootings," Framing Public Memory, in Kendall R. Phillips, ed., Framing Public Memory (Tuscaloosa: University of Alabama Press, 2004), 65-88. For a psychoanalytical viewpoint, see JoAnn Ponder, "From the Tower Shootings in 1966 to Campus Carry in 2016: Collective Trauma at the University of Texas at Austin," International Journal of Applied Psychoanalytic Studies 15:4 (2018), 1-14.

7. Yên Lê Espiritu's book, Body Counts: The Vietnam War and Militarized Refugees (Berkeley: University of California Press, 2014), uses the term organized forgetting in the context 
of the Vietnam War, in which US perspectives of the war were valorized, while the Vietnamese perspectives were actively ignored.

8. "Memorial Plaque in Tower Garden Commemorates Victims of Aug. 1, 1996 Shooting Tragedy," UT News, January 10, 2017, accessed July 7, 2019, https://news.utexas.edu/ 2007/01/10/memorial-plaque-in-tower-garden-commemorates-victims-of-aug-1-1966shooting-tragedy/.

9. On the effects of "blind-spots" related to constructing/not constructing memorials, see Trevor Hoag, "Elusive Memorials: Blind Spots, Insight, and Gun Violence at the University of Texas at Austin," InVisible Culture 19 (Fall 2013), accessed July 6, 2019, http://ivc.lib.rochester.edu.

10. A. Jason Huebinger, "Progression since Charles Whitman: Student Mental Health Policies in the 21st Century," Journal of College and University Law, 34:3 (2008), 695-716; Joe Scott-Coe, "But What Would She Say?: Reframing 'Domestic Terror' in the 1966 UT Austin Shooting," Pacific Coast Philology, 52:2 (2017), 294-313.

11. The article is based on a total of 28 interviews conducted at The University of Texas at Austin and St. Edward's University in Spring 2018 and Spring 2019.

12. Jacques Rancière, The Emancipated Spectator, trans. Gregory Elliott (London: Verso, 2009), 13.

13. Jacques Rancière, The Politics of Aesthetics: The Distribution of the Sensible, trans.

Gabriel Rockhill (New York: Continuum, 2004), 9.

14. Here Rancière is referring to an older tradition of the term, used by the Greeks, as pertaining to the body. I would like to express thanks to one of the anonymous readers for calling attention to this distinction. For further discussion, see Terry Eagleton, The Ideology of the Aesthetic (Oxford: Blackwell, 1990).

15. See "Handbook of Operating Procedures 8-1060: Campus Concealed Carry," The University of Texas at Austin, August 1, 2016, accessed November 26, 2018, https:// policies.utexas.edu/policies/campus-concealed-carry.

16. For general information as well as policy and implementation guidelines of Campus Carry at The University of Texas at Austin, see https://campuscarry.utexas.edu/, accessed March 10, 2020. 17. The University of Texas at Austin, "Handbook of Operating Procedures."

18. Interview with author, University of Texas at Austin, April 26, 2018, notes in possession of author.

19. Ibid.

20. Ibid.

21. Laws prohibiting the carrying of firearms in polling places in Texas date back all the way to 1866 , although the state did not require licensing to carry concealed handguns for personal protection until 1995. The early license holders were not allowed to bring weapons into campus buildings until the implementation of Campus Carry in 2016. See Aric Short, "Guns on Campus: A Look at the First Year of Concealed Carry at Texas Universities," Texas Bar Journal, 80:8 (2017), 516-517.

22. Interview with author, University of Texas at Austin, June 12, 2018, notes in possession of author.

23. Interview with author, University of Texas at Austin, April 4, 2018, notes in possession of author.

24. Rancière, The Emancipated Spectator, 83.

25. Public Forums $\# 1$ and $\# 2$ were organized at The University of Texas, Texas Union Ballroom on September 30, 2015 and October 5, 2015. The events were taped and transcribed. Transcriptions of the meetings in possession of the author. 
26. Interview with author, University of Texas at Austin, March 28, 2018, notes in possession of author.

27. Meara Isenberg \& Morgan O'Hanlon, “Gun Free UT Signs Face Removal after University Enforces Signage Policy," The Daily Texan, September 6, 2018, accessed July 6, 2019, https:// www.dailytexanonline.com/2018/09/06/gun-free-ut-signs-face-removal-after-university-

enforces-signage-policy.

28. "Signs on Building Window," UT NEWS, September 6, 2018, accessed July 6, 2019 https:// news.utexas.edu/key-issues/signs-on-building-windows/.

29. Sam Groves, "University Offers Little Justification in Request for Removal of Gun Free UT Signs," The Daily Texan, September 25, 2018, https://www.dailytexanonline.com/2018/09/25/ university-offers-little-justification-in-request-for-removal-of-gun-free-ut-signs, accessed July 6 , 2019.

30. Katherine Horstman and Julia O'Hanlon, “Come and Take my Gun Free UT Sign," The Daily Texan, November 4, 2018, accessed July 6, 2019. https://www.dailytexanonline.com/2018/11/04/ come-and-take-my-gun-free-ut-sign.

31. John Morton Center for North American Studies, "UT Austin Student Survey on the Campus Carry Law," 2019.

32. Interview with research team, University of Texas at Austin, April 3, 2019, notes in possession of author.

33. Interview with author, University of Texas at Austin, April 20, 2018, notes in possession of author.

34. $\quad$ https://www.encyclopediavirginia.org/

University_of_Virginia_Board_of_Visitors_Minutes_October_4-5_1824, accessed July 10, 2019.

35. Rancière, The Politics of Aesthetics, 20.

36. Ibid., "Translator's Introduction," 3.

37. Asbjørn Grønstad and Henrik Gustafsson, "Introduction," in Asbjørn Grønstad and Henrik Gustafsson, eds., Ethics and Images of Pain (New York: Routledge, 2012), Xv.

38. U.S. Court of Appeals for the Fifth Circuit, "Jennifer Glass, et al v. Ken Paxton, et al.," No. 17-50641, August 16, 2018, http://www.ca5.uscourts.gov/opinions/pub/17/17-50641-CV0.pdf.

39. Interview with author, University of Texas at Austin, April 28, 2018, notes in possession of author.

40. Although there have been minor issues with Campus Carry, such as firearms being left behind in restrooms, the pro-gun contingency's main argument in Texas is that the policy is working, as there have not been major incidents of gun-related violence, let alone a mass shooting, at Texas campuses in the years after the implementation of the legislation. For opposing views on the issue, see, for example, Florian Martin, "Two Years After Campus Carry Took Effect, Has Anything Changed?" Houston Public Media, September 27, 2018, accessed March 10, 2020, https:// www.houstonpublicmedia.org/articles/news/in-depth/2018/09/27/305798/two-years-aftercampus-carry-took-effect-has-anything-changed/ and Neelesh Rathi, "The Protests Are Gone, Guns Aren't," Daily Texan, October 14, 2019, accessed March 10, 2020. https://thedailytexan.com/ 2019/10/14/the-protests-are-gone-guns-aren\%E2\%80\%99t.

41. Pamela Collof, “The Reckoning,” Texas Monthly, March 2016, accessed July 7, 2019, https://features.texasmonthly.com/editorial/the-reckoning/. 


\section{ABSTRACTS}

This article explores everyday experiences and visual-spatial expressions related to the implementation of SB 11, the Texas Senate Bill that allows "License to Carry" (LTC) holders to bring guns onto public university campuses. In particular, it considers the ways in which members of The University of Texas at Austin community delineate their visual-spatial surroundings and sensory perceptions on campus before and after the implementation of the Campus Carry law. It considers a range of visual interventions by lawmakers and university administrators, as well as counter-visuals created by grassroots activists, faculty, and students. Moreover, it discusses the various ways in which policies are drafted to suppress awareness of firearms from the visual topography of campus space. Drawing on Jacques Rancière's work on the political dimension of aesthetics, the research presents Campus Carry as an example of a particular aesthetic-political regime created by state legislators and negotiated by the university community. The article demonstrates a tension between seeing and unseeing-remembering and forgetting-the armed campus space and the range of visual metaphors through which firearms are discussed without ever exhibiting the actual, physical object of a gun. The focus on lived experiences that explicate the ramifications of the Campus Carry legislation in Texas contributes an important case for broader analysis of U.S. gun politics and senses of security and insecurity within educational establishments.

\section{INDEX}

Keywords: aesthetics, Campus Carry, gun culture, remembering and forgetting, security and insecurity, Texas, seeing and unseeing, visual culture

\section{AUTHOR}

\section{BENITA HEISKANEN}

Benita Heiskanen is Professor of North American Studies and Director of the John Morton Center at the University of Turku, Finland. She directs a four-year research project on Campus Carry, funded by the Academy of Finland. Her previous work includes The Urban Geography of Boxing: Race, Class, and Gender in the Ring (New York: Routledge, 2012, paperback 2014). 